\title{
28 Research Suare \\ Anti Bacterial Activity of Lavandula Extracts, Pathogen and Probiotics Bacteria
}

\section{Asal khodagholi}

Azad University: Islamic Azad University

Mahdieh Soltani

Azad University: Islamic Azad University

Mohammad Mehdi Akbarin

Mashhad University of Medical Sciences

Zahra Farjami ( $\sim$ Mahsa.farjami67@gmail.com )

Mashhad University of Medical Sciences

Research

Keywords: Lavandula angustifolia, Lavandula oils, microplates MICs, anti bacterial, Probiotics

Posted Date: July 19th, 2021

DOl: https://doi.org/10.21203/rs.3.rs-709254/v1

License: (c) (1) This work is licensed under a Creative Commons Attribution 4.0 International License. Read Full License 


\section{Abstract}

Introduction: Herbs of the lavender genus are widely used today as anti-bacterial drugs in traditional medicine. Lavandula angustifolia (LA) is endemic in the Iberian Peninsula and common in Iran that belongs to the Lamiaceae family. Lavandula oils, well known for their scent and aroma, have been used in the perfumery and food industry for many years, therefore the aim of this study is the assessment of the anti-bacterial effect of LA extracts against pathogens and non-pathogen bacteria.

Methods: 96-well microplates MICs were determined by the broth microdilution method. Five Serial dilutions from 50 to $1 \mu \mathrm{g} / \mathrm{mL}$ concentrations were admitted for all bacteria which include: Escherichia Coli ATCC 25922, Enterococcus faecalis ATCC 29212, Pseudomonas aeruginosa ATCC 27853 and Staphylococcus aureus ATCC 25923, and Probiotics complex.

Results: LA watery extract demonstrate the statically inhibitory effect in just $50 \mathrm{~g} / \mathrm{L}$ concentration against E.Coli, E. Faecalis, Pu, and Probiotic $p=0.024,0.025,0.004$, and 0.012 respectively, whereas this concentration was $1 \mathrm{~g} / \mathrm{L}$ for Staph. aureus $p=0.026$. LA alcohol extracts display the same effect in $1 \mathrm{~g} / \mathrm{L}$ for all bacteria $p=0.000$.

Conclusion: Our results showed that LA in both watery and Alcohol extractions can inhibit both pathogenic and non-pathogen bacteria whereas active compounds are alcohol soluble. Long-time consumption of LA in the herbal product could disrupt normal bacteria of the gastrointestinal system.

\section{Introduction}

Now a day's, by an increase in nonstandard intake of antibiotics, antimicrobial resistance bacteria creation (AMR) changed to one the most global health hazard, which, rate of resistance bacteria species are in growth while a new generation of antibiotic compounds encounters limitation in production. The point of using these antibacterial compounds is May disrupt both pathogen and non-pathogen flora(1) (2, $3)(4,5)$. Probiotic bacteria as the most non-pathogen bacteria are live microorganisms that have a curative effect on the host immune or gastrointestinal system which are normally present in the gastrointestinal tract and include species such as Lactobacillus gasseri, Lactobacillus acidophilus, Lactobacillus Plantarum, Lactobacillus johnsonii, Lactobacillus casei $(2,4,6)$. One of the alternative treatments for AMR infections is the use of natural bactericidal compounds, which commonly are extracted from herbs(7).

Herbs of the lavender genus are widely used today as anti-bacterial drugs in traditional medicine. Lavandula (LA) belongs to a diverse genus of the Lamiaceae family, which contains more than 39 species $(8,9)$.The two main known species of LA are: Lavandulla angustifolia and Lavandullastoechas $(10,11)$. This plant is cultivated for various purposes around the world, moreover, they have advanced antioxidant, anti-inflammatory, antifungal, antibacterial, and insecticidal activities, whereas, between the two species, L. Angustifolia is more cultivated and is often used in the pharmaceutical and perfume industries $(12,13)(8)$. This plant usually well grows in Mediterranean 
climates area such as Turkey and Iran $(8,14,15)$. Traditionally LA extracts are more commonly used in the food industry as a flavoring or as a natural resource in the perfume and cosmetics industry $(8,9,16)$. Base on the antifungal, antibacterial, and anti-inflammatory effects of these plants, they could use in traditional medicine for the treatment of infectious and inflammatory diseases $(8,9,14)$. The main active substances of LA are some volatile compounds such as Linalool, Linalyl acetate, trance-ocimene, which produce a good proportion for aromatherapy and anti-bacterial treatment $(17)(8,16)$. Recently, an increase in synthetic chemical drug consumption brings some unexpected side effects such as immune system suppression and produce a wide range of antibiotic resistance bacteria. As a result, the use of medicinal herbs extracts is more commonly interest for treatments instead of chemical drugs $(18,19)(9)$. While, base on some reports the herbal treatment side effects are seems to be neglected, therefore the aim of this study is the assessment of the anti-bacterial effect of LA extracts against pathogen and nonpathogen bacteria.

\section{Material And Method}

- Plant material

Herbal samples were randomly collected during March2021 from the Northeast of Iran and were identified by naturalist botanists. The collected samples were screen for specific Lavandula angustifolia and then for about one week were naturally air-dried be stored on a low moisture place, protected from direct sunlight. Those dried plants were kept in plastic vials up to extraction time.

- Preparation of plant extract

Plant materials were dried and grind into powder form by the manual mechanical grinder. Planet powdered samples $(50 \mathrm{~g}$ ) were soaked with $500 \mathrm{~mL}$ of $99.8 \%$ ethanol (Merck, Germany, EC num: 200-5786) and were mixed continually be placed on a rotary shaker (Hitech, Germany) for $24 \mathrm{~h}$ at room temperature- protected from light. The same procedure was applied by distilled water for watery extract. Ethanol alcohol has been chosen as a solvent because of its use in form of oil for traditional medicines. Both Extracts were subsequently filtered. Rotary vacuum evaporator RV 8 V-C (IKA, Staufen Germany) was used for reconcentration of alcohol extract by low-level heating at $38-40^{\circ} \mathrm{C}$. The dried powder was resolved in PBS buffer at the original concentration afterward were stored at $4^{\circ} \mathrm{C}$ until tested.

- Microorganisms and media

Three common entheogenic gram-negative bacterial, one of the most gram-positive cocci and probiotics complex were collected in this study. Microorganism base on their American Type Culture Collection (ATCC) from Baharafshan Co-Iran purchased in the form of lyophilized strains, which contain: Escherichia Coli ATCC 25922, Enterococcus faecalis ATCC 29212, Pseudomonas aeruginosa ATCC 27853, and Staphylococcus aureus ATCC 25923. 
Probiotic was obtained from standard mixture formula. Femilacte $\AA$ is a synbiotic combination (probiotic + prebiotic) suitable for all family members and contains high amounts (around 10^9 CFU) of nine beneficial and safe bacterial strains such as Lactobacillus rhamnosus, Bifidobacterium lactis, Lactobacillus casei, Bifidobacterium bruh, Lactobacillus acidophilus, Bifidobacterium langue, Lactobacillus Plantarum, Bifidobacterium bifidum, Streptococcus thermophilus, along with fructooligosaccharide as a Prebiotic. The strains and Probiotics used in this product include the following Microorganisms that were recovered in Mueller-Hinton broth (MHB) (QUELAB, Montreal, Canada) at $37^{\circ} \mathrm{C}$ for $24 \mathrm{~h}$. Cultured bacteria adjusted for inoculum concentration by MHB, the turbidity of the microorganism suspension was obtained to a $0.5 \mathrm{McFarland}$ standard $(1.5 \times 108 \mathrm{CFU} / \mathrm{mL})$. Optical density was calculated by spectrophotometer Tajhizat Sanjesh (Esfahan-Iran) at 600nm.

- Minimum inhibitory concentration (MIC) assay

96-well microplates MICs were determined by the broth microdilution method. Five Serial dilutions (100 $\mu \mathrm{L}$ ) of all herbal extract (Watery and Alcohol) were dispersed into the plate and diluted in the MHB provide ranging from 50 to $1 \mu \mathrm{g} / \mathrm{mL}$ concentrations. Thereafter, maintained microorganism suspensions were added to the microplates then were inoculated with the final concentration $5 \times 105 \mathrm{CFU} / \mathrm{mL}$ for bacteria and Probiotics complex. Each dilution was examined triple for each bacterium. Plates were then incubated at $37^{\circ} \mathrm{C}$ for $24 \mathrm{~h}$. Microorganism expansion was calculated in terms of turbidity recorded by OD measurements at $405 \mathrm{~nm}$ BioTek ELX 800 microplate reader, (Winooski, VT). The MIC was calculated as the lowest concentration that showed $\geq 80 \%$ inhibition of microbial growth compared to extract-free growth control. All-optical densities were measured base on blank bacteria medium and herbal extracts. The bacterial suspension with an equal volume of MHB was used as positive controls for microorganism growth. The herbal extract Added to MHB without bacteria suspension used as a negative control. All data in this study were reported in the median/mode of MICs obtained from three independent experiments that were assayed in triplicate.

\section{Statistical Analysis}

All replicates were calculated for standard deviations and the mean values by using SPSS version 16 . The means differential values between groups were examined by independent sample T-test and MannWhitney $\mathrm{U}$ test followed by normal distributional analysis. The significant statistical differences were considered $p$ values $<0.05$.

\section{Results}

\section{LA watery extract results:}

Normal test statically analysis was done for all bacterial growth values in five concentration groups of watery LA extractions. One-Sample Kolmogorov-Smirnov Test showed that E. Coli and Enterococcus faecalis have nonparametric growth values $p=0.05$ and 0.004 respectively. Mann-Whitney $U$ test results declared that LA extract has a statically inhibitory effect on E. Coli and Enterococcus faecalis in just 50 
$\mathrm{g} / \mathrm{L}$ concentration, mean of bacterial $\mathrm{OD}=0.196 \pm 0.0014$ and $0.196 \pm 0.041(p=0.024$ and 0.025 respectively). These data were shown in graphs 1 and 2.

Base on the Independent Samples Test, MIC microplate analysis data demonstrate that LA watery extract has an inhibitory effect on pseudomonas aeruginosa and Probiotics in just $50 \mathrm{~g} / \mathrm{L}$ concentration by mean $0.157 \pm 0.019$ and $0.118 \pm 0.008 p=0.004$ and $p=0.012$ respectively. Staphylococcus aureus growth got stopped in $1 \mathrm{~g} / \mathrm{L}$ mean $0.621 \pm 0.03 p=0.026$.

\section{LA Alcohol extracts results:}

All bacterial growth values in the five concentration groups of alcohol LA extractions were analyzed by Normal test One-Sample Kolmogorov-Smirnov, which showed that just pseudomonas aeruginosa have non-parametric growth values $p=0.031$. Mann-Whitney $\mathrm{U}$ test results declared that LA extract has a statically inhibitory effect on pseudomonas aeruginosa in all concentrations $(50-1 \mathrm{~g} / \mathrm{L})$, the mean of bacterial $\mathrm{OD}=0.133 \pm 0.01 p=0.036$. These data were shown in graph 3 .

Independent Samples Test for MIC microplate analysis data demonstrate that LA alcohol extract has an inhibitory effect on staphylococcus aureus, E.Coli, Enterococcus faecalis, and Probiotics in all concentration groups $(p=0.000,0.000,0.000$, and 0.001 respectively).

\section{Conclusion}

Herbs of the lavender genus are widely used today as anti-bacterial drugs in traditional medicine. Lavandula oils, well known for their scent and aroma, have been used in the perfumery and food industry for many years $(17,20,21)$. As our data demonstrate above LA extract have a proper antibacterial activity, where $50 \mathrm{~g} / \mathrm{L}$ concentration of LA watery extract can inhibit all examined bacteria while for staphylococcus aureus this amount was $1 \mathrm{~g} / \mathrm{L}$. this data suggests that LA watery extract have dose depended on antibacterial activity, which lower LA concentration have not stopped the bacterial growth or can prompt their division. The $1 \mathrm{~g} / \mathrm{L}$ concentration of LA alcohol extract displayed the same inhibitory activity therefore it seems LA alcohol extract has the strongest anti-bacterial effect than watery form. This data suggest that LA's main anti-bacterial compounds may be alcohol soluble. Furthermore, Probiotics as non-pathogenic microorganisms can inhibit such as pathogenic ones, therefore long-time consumption of LA in the herbal product could disrupt normal bacteria of the gastrointestinal system.

Our results showed that LA in both watery and Alcohol extractions can inhibit both pathogenic and nonpathogen bacteria in $50 \mathrm{~g} / \mathrm{L}$ concentration whereas $1 \mathrm{~g} / \mathrm{L}$ of alcoholic extraction demonstrates the same effect.

\section{Declarations}

\section{Ethics approval and consent to participate}

Not applicable 


\section{Consent for publication}

Will be sent in future

\section{Availability of data and materials}

The datasets used and/or analysed during the current study are available from the corresponding author on reasonable request.

\section{Competing interests}

The authors declare that they have no competing interests

\section{Funding}

This is the self fund study

\section{Authors' contributions}

MS: Is providing material and help to perform this study

AK: Is providing material and help to perform this study

ZF: Is analyzing data and provide the herbal extract

MMA: is performing, deigning and writing the article

\section{Acknowledgment:}

We desire to announce our particular gratitude to all research team members who incorporate, facilitate and support this project especially Dr. Amini Laboratory for equipment preparation.

\section{References}

1. Draper K, Ley C, Parsonnet J. Probiotic guidelines and physician practice: a cross-sectional survey and overview of the literature. Beneficial microbes. 2017;8(4):507-19. Epub 2017/06/18.

2. Hill C, Guarner F, Reid G, Gibson GR, Merenstein DJ, Pot B, et al. Expert consensus document. The International Scientific Association for Probiotics and Prebiotics consensus statement on the scope and appropriate use of the term probiotic. Nature reviews Gastroenterology hepatology. 2014;11(8):506-14. Epub 2014/06/11.

3. Jeżewska-Frąckowiak J, Seroczyńska K, Banaszczyk J, Jedrzejczak G, Żylicz-Stachula A, Skowron PM. The promises and risks of probiotic Bacillus species. Acta Biochim Pol. 2018;65(4):509-19. Epub 2018/12/07.

4. Ritchie ML, Romanuk TN. A meta-analysis of probiotic efficacy for gastrointestinal diseases. PloS one. 2012;7(4):e34938. Epub 2012/04/25. 
5. Zawistowska-Rojek A, Tyski S. Are Probiotic Really Safe for Humans? Polish journal of microbiology. 2018;67(3):251-8. Epub 2018/11/20.

6. Schoster A. Probiotic Use in Equine Gastrointestinal Disease. The Veterinary clinics of North America Equine practice. 2018;34(1):13-24. Epub 2018/02/07.

7. Dwyer AV, Whitten DL, Hawrelak JA. Herbal medicines, other than St. John's Wort, in the treatment of depression: a systematic review. Alternative medicine review: a journal of clinical therapeutic. 2011;16(1):40-9. Epub 2011/03/29.

8. Insawang S, Pripdeevech P, Tanapichatsakul C, Khruengsai S, Monggoot S, Nakham T, et al. Essential Oil Compositions and Antibacterial and Antioxidant Activities of Five Lavandula stoechas Cultivars Grown in Thailand. Chem Biodivers. 2019;16(10):e1900371. Epub 2019/08/30.

9. Nunes R, Pasko P, Tyszka-Czochara M, Szewczyk A, Szlosarczyk M, Carvalho IS. Antibacterial, antioxidant and anti-proliferative properties and zinc content of five south Portugal herbs. Pharmaceutical biology. 2017;55(1):114-23. Epub 2016/12/08.

10. Altaei DT. Topical lavender oil for the treatment of recurrent aphthous ulceration. American journal of dentistry. 2012;25(1):39-43. Epub 2012/05/09.

11. Giovannini D, Gismondi A, Basso A, Canuti L, Braglia R, Canini A, et al. Lavandula angustifolia Mill. Essential Oil Exerts Antibacterial and Anti-Inflammatory Effect in Macrophage Mediated Immune Response to Staphylococcus aureus. Immunol Investig. 2016;45(1):11-28. Epub 2016/01/06.

12. Aboutaleb N, Jamali H, Abolhasani M, Pazoki Toroudi H. Lavender oil (Lavandula angustifolia) attenuates renal ischemia/reperfusion injury in rats through suppression of inflammation, oxidative stress and apoptosis. Biomedicine pharmacotherapy = Biomedecine pharmacotherapie. 2019;110:919. Epub 2018/11/20.

13. Basch E, Foppa I, Liebowitz R, Nelson J, Smith M, Sollars D, et al. Lavender (Lavandula angustifolia Miller). J Herbal Pharmacother. 2004;4(2):63-78. Epub 2004/09/15.

14. Gursoy UK, Gursoy M, Gursoy OV, Cakmakci L, Könönen E, Uitto VJ. Anti-biofilm properties of Satureja hortensis L. essential oil against periodontal pathogens. Anaerobe. 2009;15(4):164-7. Epub 2009/03/17.

15. Kirmizibekmez H, Demirci B, Yeşilada E, Başer KH, Demirci F. Chemical composition and antimicrobial activity of the essential oils of Lavandula stoechas L. ssp. stoechas growing wild in Turkey. Nat Prod Commun. 2009;4(7):1001-6. Epub 2009/09/08.

16. Bajalan I, Rouzbahani R, Pirbalouti AG, Maggi F. Chemical Composition and Antibacterial Activity of Iranian Lavandula $\times$ hybrida. Chemistry \& biodiversity. 2017;14(7). Epub 2017/03/18.

17. Velasco-Rodríguez R, Pérez-Hernández MG, Maturano-Melgoza JA, Hilerio-López ÁG, Monroy-Rojas A, Arana-Gómez B, et al. The effect of aromatherapy with lavender (Lavandula angustifolia) on serum melatonin levels. Complement Ther Med. 2019;47:102208. Epub 2019/11/30.

18. Rai VK, Sinha P, Yadav KS, Shukla A, Saxena A, Bawankule DU, et al. Anti-psoriatic effect of Lavandula angustifolia essential oil and its major components linalool and linalyl acetate. $J$ Ethnopharmacol. 2020;261:113127. Epub 2020/07/06. 
19. Watson K, Hatcher D, Good A. A randomised controlled trial of Lavender (Lavandula Angustifolia) and Lemon Balm (Melissa Officinalis) essential oils for the treatment of agitated behaviour in older people with and without dementia. Complement Ther Med. 2019;42:366-73. Epub 2019/01/24.

20. Caputo L, Souza LF, Alloisio S, Cornara L, De Feo V. Coriandrum sativum and Lavandula angustifolia Essential Oils: Chemical Composition and Activity on Central Nervous System. International journal of molecular sciences. 2016;17(12). Epub 2016/12/06.

21. Cavanagh HM, Wilkinson JM. Biological activities of lavender essential oil. Phytother Res. 2002;16(4):301-8. Epub 2002/07/12.

\section{Figures}

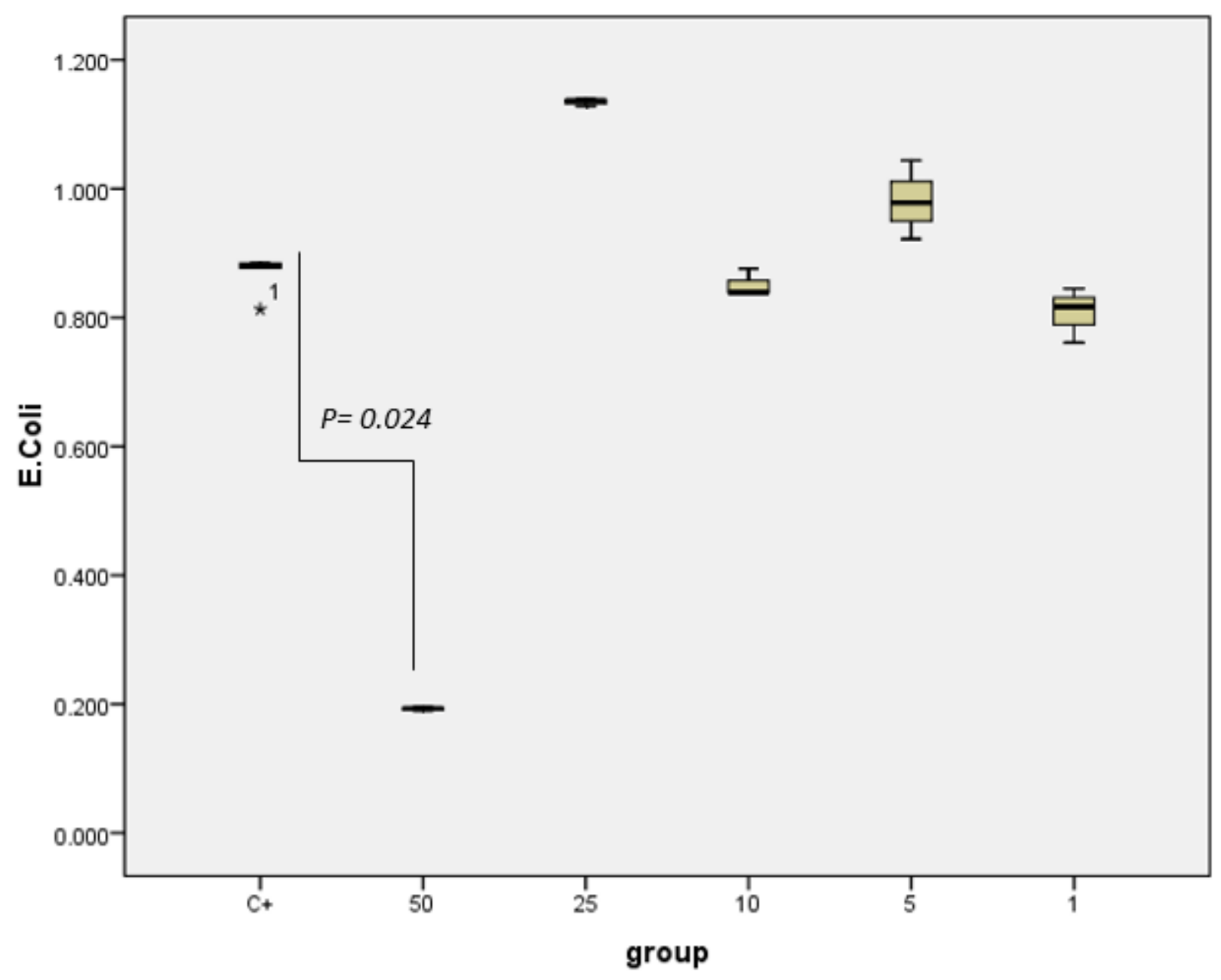

\section{Figure 1}

E.Coli growth values in LA extract showed that just $50 \mathrm{~g} / \mathrm{L}$ concentration can significantly inhibit bacterial growth. 


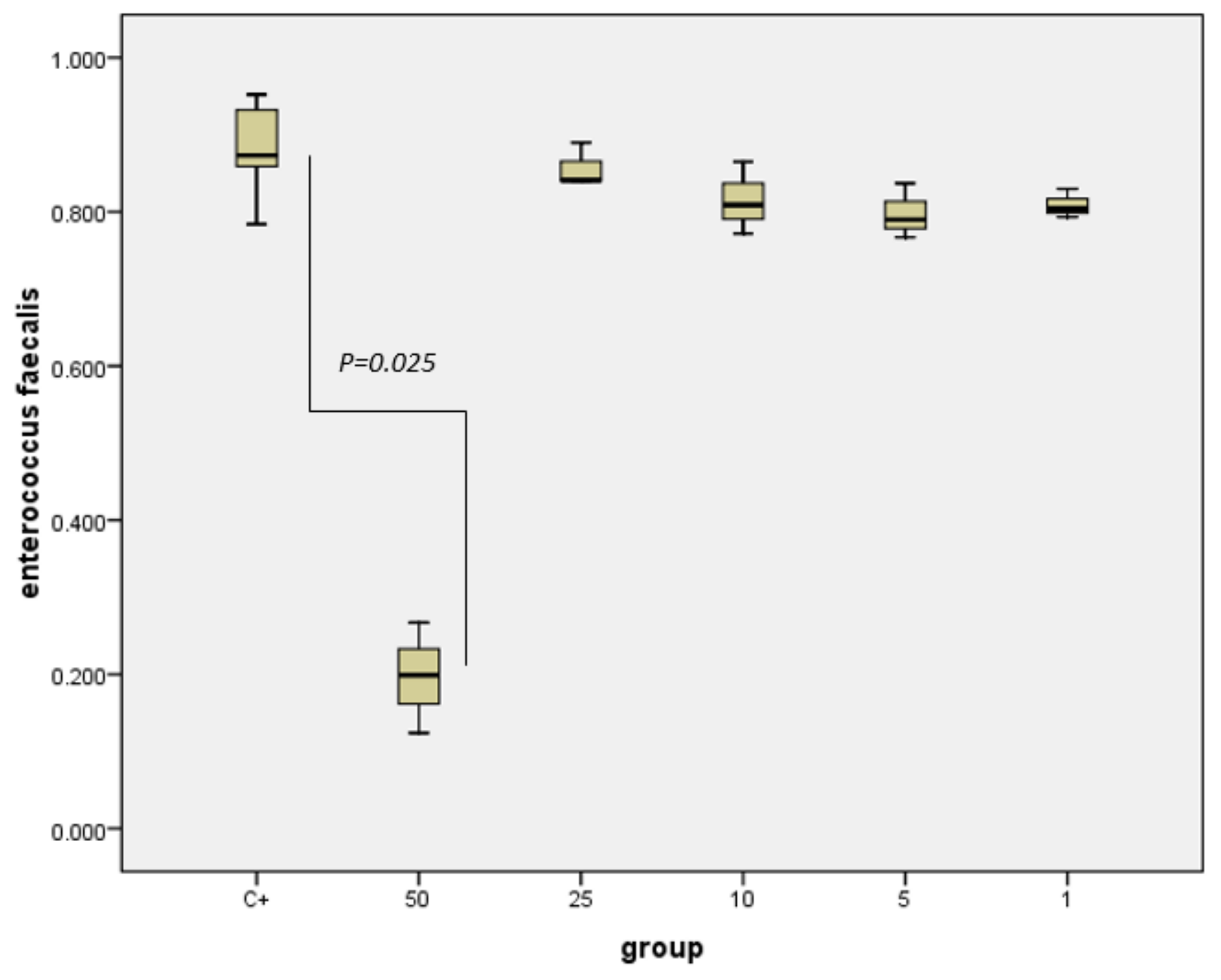

Figure 2

Enterococcus faecalis growth values in LA extract showed that just $50 \mathrm{~g} / \mathrm{L}$ concentration can significantly inhibit bacterial growth. 


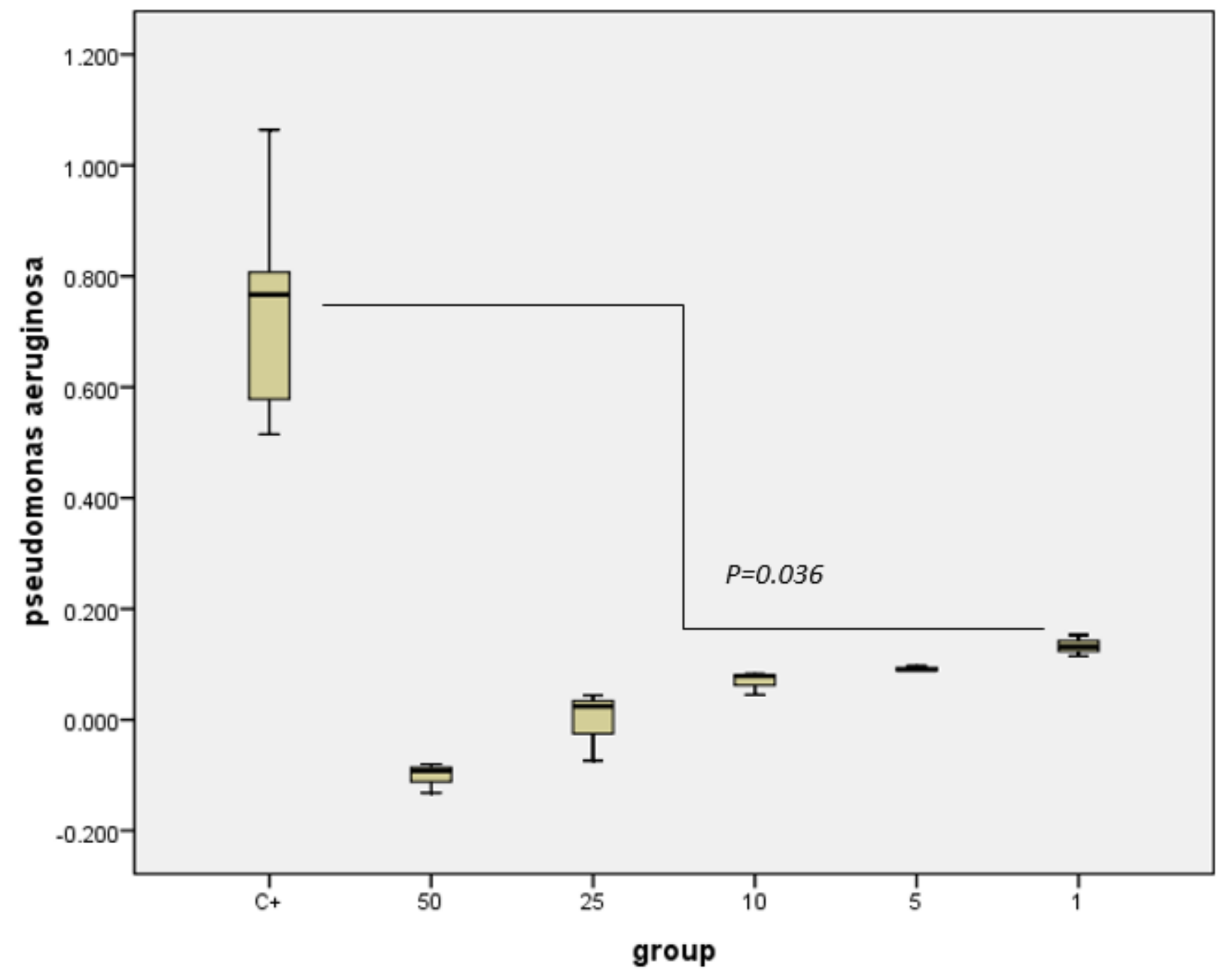

Figure 3

Pseudomonas aeruginosa growth values in LA extract showed that at least $1 \mathrm{~g} / \mathrm{L}$ concentration can significantly inhibit bacterial growth. 